\title{
HARD X-RAYS FROM THE SOUTHERN SKY
}

\author{
WALTER H. G. LEWIN, JEFFREY E. MCCLINTOCK and WILLIAM B. SMITH \\ Massachusetts Institute of Technology, Cambridge, Mass., U.S.A.
}

\begin{abstract}
On March 20,1969, we scanned the Southern sky for 8 hours in a manner similar to that during our October 15,1967 observations. ${ }^{*}$ A quick look at the data shows clearly that the brightness of Cen XR-2 in the energy range above $20 \mathrm{keV}$ has significantly decreased since our first observation. At this stage of the data analysis we can put an upper limit on the intensity of Cen XR-2 which is $\frac{1}{3}$ the intensity observed by us on October 15, 1967. From further data analyses we will be able to determine the intensity of the source more precisely.**

During the same flight we observed Sco X-1, Nor XR-2, and the sources M-1, M-2, M-3, and M-4. ${ }^{\ddagger}$ Results on these observations will become available by May 1970 .
\end{abstract}

* Lewin, W. H. G., Clark, G. W., and Smith, W. B.: 1968, Astrophys. J. 152, L49.

** The final results on Cen XR-2 will be available in Febr. 1970; they will be published shortly thereafter.

‡ Lewin, W. H. G., Clark, G. W., Gerassimenko, M., and Smith, W. B.: 1969, Nature 223, 1142. 